2 inches from the tragus and was visible. The patient felt " much better." The wound was repacked with wet gauze. A good view of the aqueduct and labyrinthine cavity was obtained through the meatal tube. on the 13 th the patient had slept well from 9 P.M. to 2 A.M. She had been restless since and had pain on the top of the head, which was worse during the day, especially if excited or moved in bed. There was no vomiting; the bowels were opened. She felt better when quiet. The temperature at 7 A.M. was $101^{\circ}$ (it has risen $2^{\circ}$ ); in the afternoon it was $100^{\circ}$. The pulse was 86 and the respirations were 28. The wound was dressed at 5 P.M. ; all gauze was removed. The cavity was irrigated with peroxide of hydrogen lotion, dried, and inspected. The aqueduct and vestibular cavity were in view, The cavity was packed with cyanide gauze soaked in biniodide lotion. The rubber ring tube was removed. The packing in the post-aural wound was discontinued to-day. On the 14th the wound was dressed as before. The post-aural wound was closed with plastic exudate. The patient still complained of pain on the top of the head. The temperature was $101.6^{\circ}$ and the pulse was 88 . She had slept from 9 P.M. to 5 A.M. On the 15 th the wound was dressed. The patient was interrogated and she stated that the pain on the vertex greatly increased when the gauze was withdrawn the pain on the vertex greatly iucreased when the gauze was witbdrawn (from cochlea cavity) and when repacked into that cavity. From not due to any intracranial lesion. She stept well and took food well. She sat up in bed cheerfully when dressed but food well. She sat up in bed cheerfully when dressed but preferred to be kept quiet and held her head in her hands afterwards. There had been no vomiting. No gauze was inserted into the cochlea cavity to-day. On the 17th a leucocyte count gave 11,000. A complete survey was made. Nothing abnormal could be discovered. On the 19th ophthalmoscopic examination was nil except for an old patch in the
choroid. The temperature was still elevated, though the patient showed no evidence in her general condition of fever. It was difficult to correlate the cephalalgia and raised temperature with the general to correlate the cephalalgia and raised temperature with the general improvement in the patient. Lumbar puncture was performed and obtained, which was examined cytologically, bacteriologically, and chemically but no abnormal constituents were discovered. It was eventually discovered that the patient, as she improved, endeavoured eventually discovered, that the patient, as she improved, endeavoured to keep herself interesting by warming her thermometers, on some occasions to $104^{\circ}$ and $106^{\circ}$. She overstepped the mark by raising the temperature to $110^{\circ}$ without evincing any sign of pyrexia. This is the more interesting as showing an abnormal psychosis, which was recognised early in the management of her case, and rendered the diagnosis of labyrinthine disease especially difficult to make, but which disease has proved indisputably to exist by the histological preparations of the cochlea which I made. By Sept

and the patient had completely recovered. CASE 3. Chronic suppurative otitis media; mastoid fistula; labycanals and vestibule. presentation of and superior and cochlea recovery,-The patient, a girl, aged five facial nerve and cocheas mitted to the Huelina Hospital for Sick Children, under my care in Nuvember, 1904, with a discharge from the right external auditory meatus and a superficial mastoid fistula, which, according to her mother's account, had existed since the child was six months old. 'The child had complained of the room going round and she was very deaf; the usual tests could not be applied. Stacke's operation was performed. The mastoid fistula was found entering the accessory cells through the posterior wall of the osseous meatal canal. The antrum which was large, was full of soft cholesteatomatous material and granulation tissue, from which a variety of organisms was cultiof the bony walls, so that the curette could be used freely. The dura mater of the middle and posterior cranial fossa was freely exposed and presented a normal appearance. After freely opening the attic and removing overhanging bone a survey of the inner wall of the antrum and tympanum revealed an erosion of the eminentia arcuata externa. A fine probe was passed into the opening in the outer crus of the external canal forwards and entered the vestibule. The probe was then removed and passed into the fenestra ovalis. No resistance was encountered, no remains of the stapes could be found, and the probe readily entered the vestibule below the Fallopian aqueduct. The outer limb of the superior and external semicircular canal, with the ampulla and intervening bone were removed with a fine gouge free drainage of the vestibule was obtained both above and below the facial nerve. After curetting the mucosa of the tympanum freely and removal of all débris a somewhat large meato-conchal flap was cut and turned upwards. The post-aural wound was closed by suture and and turned upward whe post-aural wound was closed

The after-history of the healing process of this operation on the right ear was uneventful and by February. 1905, the cavity was comright ear was uneventful and by February, 1905, the cavity was com-
pletely cicatrised. There was never at any stage the slightest suspicion of facial paralysis or other untoward symptom. In December, 1904, while in hospital and convalescent from the radical operation on the right ear, the child developed an acute staphylococcal mastoiditis on the left side upon which I performed Schwartze's operation. This did not interfere with the result of the previous operation on the right side and the child made a complete recovery.

Queen Anse-street, W.

\section{TWENTY-SIX CASES IN WHICH BOTH EYES WERE OPERATED ON FOR SENILE CATARACT.}

BY ARTHUR O. ROPER, F.R.C.S. EDIN.,

SURGEON TO THE WEST OF ENGIAND EXE INFIRMARY.

IN recently tabulating the results of 152 cataract extractions I found that $I$ had operated upon the second eye in 26 persons, one-sixth of the total number of operations. I regret that my original tables do not enable me to say whether the eyes were right or left and I have therefore entered them in the following list as first and second. the order in which they were operated upon, at intervals varying from three months to five years.

\begin{tabular}{|c|c|c|c|c|c|c|}
\hline \multirow{2}{*}{ Case. } & \multirow{2}{*}{ Sex. } & \multirow{2}{*}{ Age. } & \multicolumn{3}{|c|}{ Results. } & \multirow[b]{2}{*}{ Remarks. } \\
\hline & & & $\begin{array}{l}\text { First } \\
\text { eye. }\end{array}$ & Remarks. & $\begin{array}{c}\text { Second } \\
\text { eye. }\end{array}$ & \\
\hline 1 & F. & 70 & $\frac{6}{3}$ & - & $\frac{6}{6}$ & - \\
\hline 2 & $\mathbf{M}$. & 57 & $\frac{6}{9}$ & - & $3^{6} 8$ & 一 \\
\hline 3 & M. & 43 & $\frac{6}{3}$ & - & 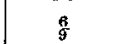 & 一 \\
\hline 4 & M. & 61 & $2^{6} \mathrm{~F}$ & - & $1^{\frac{6}{2}}$ & - \\
\hline 5 & M. & 69 & $x^{6}=$ & - & $I^{6} 8$ & - \\
\hline 6 & M. & 76 & 26 & - & Nocord. & $\begin{array}{l}\text { Was taken ill ir } \\
\text { hospital ; sen } \\
\text { home and died } \\
\text { in a few weeks. }\end{array}$ \\
\hline 7 & M. & 53 & $\frac{6}{6}$ & $\begin{array}{c}\text { Mr. J. Bankart's } \\
\text { operation. }\end{array}$ & $\frac{6}{6}$ & - \\
\hline 8 & M. & 59 & $\frac{6}{5}$ & - & $\frac{6}{5}$ & - \\
\hline 9 & F. & 67 & $3^{6} 6$ & 一 & $3^{6} 8$ & Diabetic. \\
\hline 10 & $\mathbf{M}$. & 52 & $\frac{6}{6}$ & - & $1_{2}^{6}$ & - \\
\hline 11 & F. & 38 & $\frac{b}{6}$ & - & $3^{6} 6$ & $\begin{array}{c}\text { Probably an } \\
\text { amblyopic eye. }\end{array}$ \\
\hline 12 & F. & 64 & $\frac{6}{6}$ & - & $\frac{6}{6}$ & - \\
\hline 13 & M. & 69 & $\frac{6}{3}$ & $\begin{array}{c}\text { Reduced by illness } \\
\text { to } \frac{1}{6 \gamma} .\end{array}$ & $\frac{1}{60}$ & $一$ \\
\hline 14 & M. & 62 & $\frac{6}{4}$ & - & 96 & - \\
\hline 15 & $\mathbf{M}$. & 53 & $\frac{6}{6}$ & - & $\frac{6}{5}$ & 一 \\
\hline 16 & F. & 66 & 8 & 一 & $\frac{6}{6}$ & - \\
\hline 17 & F. & 53 & $\frac{6}{9}$ & - & $\frac{8}{9}$ & - \\
\hline 18 & F. & 46 & $\frac{6}{9}$ & - & $\frac{6}{9}$ & - \\
\hline 19 & $\mathbf{M}$. & 72 & $\frac{6}{9}$ & - & $\frac{6}{9}$ & 一 \\
\hline 20 & M. & 56 & 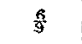 & - & $\frac{6}{6}$ & 一 \\
\hline 21 & M. & - & $\frac{6}{6}$ & $\begin{array}{c}\text { Mr. C. Higgens's } \\
\text { operation. }\end{array}$ & $\frac{6}{6}$ & - \\
\hline 22 & $\mathbf{M}$. & 73 & $2 \frac{R}{2 x}$ & Opacities. & $\frac{6}{60}$ & Opacities. \\
\hline 23 & M. & 60 & $I^{6}$ & - & $1^{6} 8$ & Choroiditis. \\
\hline 24 & F. & 67 & $\frac{6}{x^{6} \varepsilon}$ & At Moorfields. & $I^{6}$ & - \\
\hline 25 & $\mathbf{M}$. & 52 & $\frac{6}{6}$ & - & $\frac{6}{6}$ & - \\
\hline 26 & M. & 70 & $\frac{6}{18}$ & $\begin{array}{c}\text { Mr.L. H. Tosswill's } \\
\text { operation. }\end{array}$ & $1^{6} 8$ & - \\
\hline
\end{tabular}

Certain of these cases are of especial interest inasmuch as $I$ operated on the second eye only. In Cases 7, 21, 24, and 26 the vision of the two eyes after operation is the same and in each case I was the second operator. I remember well approaching Case 7 with considerable trepidation inasmuch as my predecessor, Mr. Bankart, had obtained a $\frac{6}{5}$ result without astigmatism by the simple extraction without iridectomy. I had but recently succeeded to the post of full surgeon to the Eye Infirmary and tried to persuade the man that he had better rest content with the perfect result already obtained but he was determined to have the use of both his eyes, and I had to do it. I also did, as I generally do, the simple operation and had the satisfaction-or was it the relief ?-of seeing his vision with a simple spherical lens gradually improve to every letter of $\frac{6}{5}$. Perhaps the most interesting point in the case is that two operators should have avoided astigmatism in one pair of eyes ; or, conversely, that one pair of eyes should have avoided astigmatism at the hands of two operators. Case 21 had been operated on by Mr. Higgens with a $\frac{6}{6}$ result when he came under me at the eye infirmary, and I got the same. Case 24 was operated on at Moorfields with a $\frac{6}{T^{2}}$ result. The patient did not know (such is fame!) the name of the operator. My result was $-\frac{6}{2}$. Case 26 had been operated on by my colleague, Mr. Tosswill and had $\frac{6}{18}$. I certainly did hope that I might be able to "go one better," but in the end no blandishments (or lens) would induce the patient to exceed the fourth line on the test card.

Case 13 is interesting from a different point of view. I operated on the first eye in 1902 with a $\frac{6}{9}$ result. The sight remained good until the winter of 1905-06, when the patient had a :-erious illness, broncho-pneumonia with pleuris $y$, probably influenzal in origin, from which he hardly recovered. Sight began to fail during convalescence, and when it was re ${ }^{2}$ uced to ${ }_{6}^{x} \delta$ he came to me about it. I could see nothing whatever amiss with the eye, but did not feel hopeful about it on account of having once or twice seen normal eyes in old people go blind from no discoverable cause. I put him on tonics-arsenic, strychnine, and so forth-but though he 
recovered bis bealth and strength he gained no sight. The other eye held a promising-looking cataract and the light projection was good, so I advised its extraction and performed the operation. The course of the case was fairly normal and the result was a good eye with media clear and fundus quite normal, but $V .=\frac{1}{60}$. I frequently see this man. He is able to get about and to do his work as a pianotuner and teacher of music in a small way and he has, so far as I know, no other lesion from his attack of influenza.

Two other cases only are worthy of special notice. No. 9 is a diabetic and there is no discoverable reason in her eyes, which are surgically excellent, for the poor result. In No. 11 there is good reason for thinking that the second eye was always amblyopic from squint, and she is also interesting in that she has borne four children who have been the subjects of lamellar cataract and npon whom I have operated. Her fifth and youngest is up to now free from cataract but has not yet reached the age at which the others developed it.

The general conclusion at which I arrive from this small series of cases is that one may reasonably hope, other things being equal, for at least as good a result from the second operation as from the first, the figures working out as follows :-

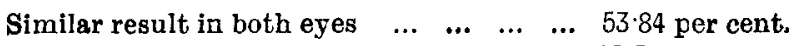

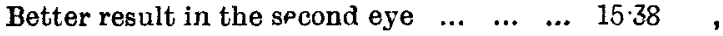

$$
\begin{aligned}
& \begin{array}{llllllllll}
\text { Worse result } \ldots & \ldots & \ldots & \ldots & \ldots & \ldots & \ldots & \ldots & 27 & 23
\end{array} \\
& \text { No record of second eye }
\end{aligned}
$$

This gives 69 per cent. of results at least as good in the second eye as in the first and if the two doubtful cases, Cases 11 and 13, are eliminated the figures will be better still.

$$
\text { Exeter. }
$$

\section{COMPENSATORY COLLATERAL CIRCULA- TION WITH "CAPUT MEDUS $\$$ " IN CIRRHOSIS OF THE LIVER WITHOUT ASCITES.}

By U. N. BRAHMACHARI, M.A., M.D., TEACHER OF MEDICINE AT THE CAMPBELL MEDICAL SCHOOL, CALCUTMA.

CASES of cirrhosis of the liver without ascites have been occasionally met with. Such cases are of special interest, as their occurrence gave rise to the idea of the DrummondTalma-Morison operation. ${ }^{l}$ Generally speaking, the collateral circulation in cirrhosis of the liver is not capable of carrying off all the surplus of blood and of re-establishing a normal vascularity and in this way removing the ascites. ${ }^{2}$ The latter, according to some, occurs in at least 80 per cent. of the cases. ${ }^{3}$ The number must be greater still when we consider those cases in which there is complete absence of hæmatemesis and melæna which frequently vary inversely with the amount of ascites present. The following case is therefore of considerable interest, showing a perfect collateral circulation without the least ascites and without any hæmatemesis and melæna.

The patient, a Bengalee, aged 35 years, was first examined by me about four years ago for the treatment of enlarged spleen. He gave a history of attacks of fever resembling malaria. There was no history of hæmatemesis, melæna, or jaundice. On examination the superficial veins of the abdomen were found enormously enlarged, especially the right epigastrics, which were tortuous and very prominent (Fig. 1). The veins round the umbilicus were somewhat dilated. There was a mark of a scar in the right hypochondrial region - the result of an operation in the Medical College Hospital, Calcutta, for an inflamed thrombus in the dilated veins situated here. The spleen was enlarged, extending about two inches below the costal arch. The liver dulness extended from the seventh intercostal space to one inch below the costal arch. The left lobe of the liver felt hard and rough. There was no ascites. A loud systolic bruit was audible over the right superficial and superior epigastric veins. A systolic bruit was also audible at the pulmonary area of the heart. The patient was somewhat anæmic and had some evening pyrexia. Digestion was good.

1 Brit. Mer. Jour., September, 1896.

2 Nothnagel's Encyclopædia of Practical Medicine (Diseases of the Liver, \&c.).

\footnotetext{
3 Allbutt's System of Medicine, vol, iv.
}

The urine was scanty and high-coloured. The patient was under my observation for some months. The fever gradually disappeared, the appetite increased, and the only symptom which afterwards he complained of was the presence of the enormously dilated veins. Since then I have seen the patient from time to time improved in general health and without any ascites.

\section{FIG. 1.}

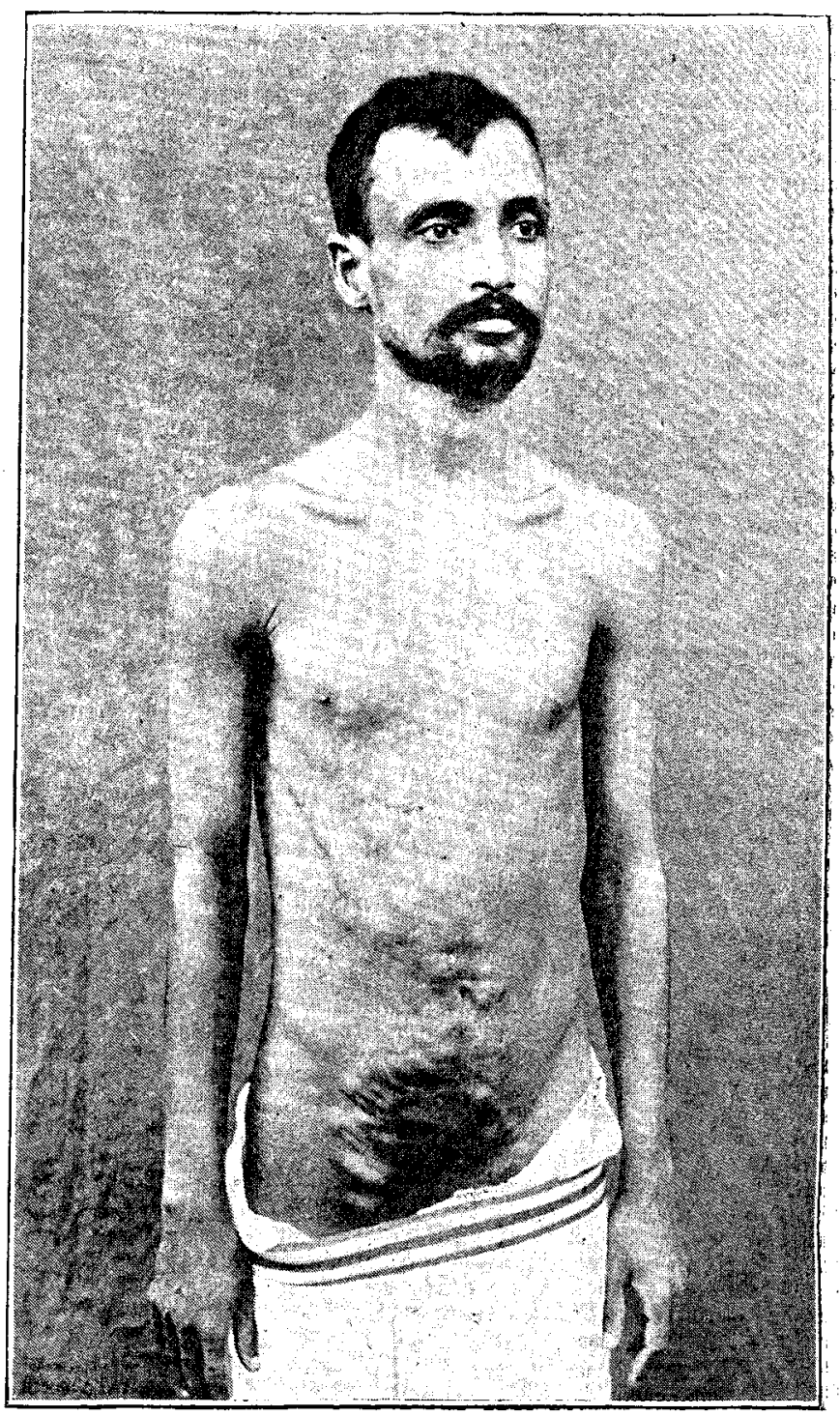

Cirrhosis of the liver without ascites. 1903.

The patient came to me the last time in March, 1907, complaining of the enlargement of the veins in the abdominal wall, which were a source of inconvenience to him and which were getting so progressively enlarged that he feared they might rupture. He asked for their complete removal by surgical interference. He looked better in health than when I saw him, about four years previously. He was only slightly anæmic, the systolic bruit at the pulmonary region of the heart having completely disappeared. The spleen extended two inches below the costal arch. The liver dulness was smaller than before and the edge of the liver was not felt below the costal arch. The dulness could just be made out in the seventh intercostal space in the right mammary line. There was no ascites. The patient had no fever and his appetite was good. The following was the oondition of the venous anastomosis in the abdominal wall (Fig. 2). 1. The right superficial epigastric was enormously dilated, looking almost like coils of intestines and anastomosing with the superficial branches of the superior epigastric which were also very much enlarged. 2. The right superficial epigastric anastomosed directly with the branches of the long thoracic which was also very prominent and enlarged. 3. The left superficial epigastric was more dilated and the anastomosis between it and the left superior epigastric more prominent than when observed abont four years previously. 4. The presence of dilated veins round the umbilicus gave rise to a well-marked " caput Medusw.'

One point that struck me was the fairly good health which the patient was enjoying during all these years. Could the 